This is a pre-publication version (i.e. prior to final edit). If possible, please access the final version of the article, which was published as:

Robertson P.J. (2013). Career guidance and public mental health. International Journal for Educational and Vocational Guidance, 13, 2, pp. 151-164. DOI: 10.1007/s10775-013-9246-y 


\title{
Career guidance and public mental health
}

\begin{abstract}
Career guidance may have the potential to promote public health by contributing positively to both the prevention of mental health conditions and to population level well-being. The policy implications of this possibility have received little attention. Career guidance agencies are well placed to reach key target groups. Producing persuasive evidence to support claims of health outcomes from guidance is problematic. Although limited, there are some studies of health impacts from employment related interventions, suggesting it is not impossible to generate such evidence. There is a need to develop an evidence base addressing well-being outcomes which may require adopting health-style research methods. There is also a need to open a dialogue with policy makers concerning the potential for career guidance to contribute to public mental health.
\end{abstract}

\section{Introduction: the neglect of health issues}

Issues of mental well-being have attracted little attention in career guidance policy making. Summarising international reviews by the Organisation of Economic Co-operation and Development (OECD), the European Commission and the World Bank, Watts and Sultana (2004) found that policies across 37 nations had converged on policy goals related to lifelong learning, the labour market and social equity. More recent studies (e.g. CEDEFOP, 2011; European Lifelong Guidance Policy Network, 2010) and international handbooks for policy makers (Hanson, 2006; OECD, 2004) also feature these central objectives.

Health outcomes are largely absent from this policy discourse. This is remarkable in the light of three observations. Firstly, the burden of disease associated with mental health conditions is very great indeed. The World Health Organisation (WHO) suggest that one person in four will develop a mental health related condition in their lifetime, and that these disorders account for $13 \%$ of the global burden of disease assessed by Disability Adjusted Life Years (DALYs) lost due to diseases across the planet (WHO, 2004a). Their projections suggest that depression may be the leading cause of 
disability by 2030 (WHO, 2011). Secondly, there is overwhelming evidence that unemployment is associated with psychological distress and increased incidence of mental health conditions (McKeeRyan, Song, Wanbeg, \& Kinicki, 2005; Paul \& Moser, 2009; Warr, 2007), and that more generally work and worklessness are deeply connected to health (Bambra, 2011).

Thirdly, the global down turn in economic activity since 2008 continues to present a significant challenge to labour markets. The International Labour Organisation (ILO, 2012) produce headline figures suggesting that the global unemployment remains around $6 \%$, with a stock of 200 million people out of work. An additional 400 million will join them in the next decade unless enough new jobs are created, which seems unlikely with current economic growth rates. This is a cause for concern given the consensus in the literature that the health and well-being of the unemployed is worse than that of the employed (Waddell \& Burton, 2006) and the evidence that some causes of mortality, notably suicide, increase during a recession (e.g. Stuckler Basu, Suhrcke, Coutts, Mckee et al., 2009). If the career guidance community is to be concerned with issues of work and worklessness, it must concern itself with health also. At this time it seems particularly unwise to ignore the powerful connections that link employment and education to health and well-being.

\section{Well-being as a goal of public policy}

To a great extent, the impetus to consider well-being as a goal of policy has come from positive psychology (e.g. Delle Fave \& Massimini, 2005; Pavot \& Diener, 2004; Veenhoven, 2004). Diener and Seligman (2004) are perhaps the most persuasive advocates of this position. They point out that in spite of a general trend towards rising prosperity in developed countries in the post-war period, measures of positive well-being over the same period have remained more or less constant (an observation first made by Easterlin, 1974). They also suggest that, notwithstanding the fluctuations associated with the economic cycle, there is a gradual trend towards greater reporting of mental health conditions, notably depression. This underpins the case that there has been an over-emphasis on economic growth and a false assumption that it equates with improvements in well-being.

They argue for systematic and consistent use of measurements of well-being by governments. Such measures could steer policy to improve people's lives more accurately than the exclusive use of 
measures of economic growth, such as Gross Domestic Product (GDP), which is adrift from measuring societal success in developed nations. This argument challenges fundamental assumptions in economics concerning the nature of utility, and the use of monetary measures as a proxy for wellbeing. It has successfully influenced some economists (e.g. Layard, 2005; The Economist, 2006).

That which is measured is important, and the UK has made steps towards exploring wellbeing as a goal of policy and finding ways of capturing it (Donovan \& Halpern, 2002; Halpern, 2010). A review of methodologies by the Office for National Statistics (ONS, 2011) led to the selection of well-being measures which now form part of the Integrated Household Survey of the UK population. This can be seen in a wider context; most notably Nicolas Sarkozy initiated the international Stiglitz Commission exploring an expansion from GDP measurement into measures of quality of life (Stiglitz, Sen \& Fitoussi, 2009).

These developments are not uncontroversial. The increasing focus on well-being in policy has provoked opposition from a variety of perspectives. Critics from a neo-liberal perspective are suspicious that it may be used as a justification for economic interventionism (e.g. Booth, 2012). Others are suspicious of emotional management practices, for example Ecclestone and Hayes (2008) who object to the encroachment of therapy into education. Critics also come from within psychotherapy and psychology, with some responding defensively to a new movement (e.g. Lazarus, 2003, who provides a thorough but unbalanced critique). Others are more constructive, such as the existential therapist van Deurzen (2009) who questions an excessive focus on happiness, arguing that experiencing and integrating negative emotions is a healthy process. Even those interested in wellbeing accept that it can be a politically malleable construct in policy discourse (e.g. Field, 2009) and that some caution is needed in questioning the evidence base before making policy recommendations (Bok, 2010).

\section{Key issues in public mental health}

International sources emphasize the importance of mental health promotion and illness prevention. The World Health Organisation (e.g. WHO 2002; 2004b; 2004c), and the European Union (Jané-Llopis \& Anderson, 2005) make it clear that these should be priority areas for national 
health policy formation, and that an evidence-based approach should be adopted. However, mental health tends to be under-funded relative to the burden of disease it represents, and mental health promotion in particular is neglected (WHO, 2005).

Scholars such as Keyes (2002) and Huppert (2004; 2005) adopt an epidemiological perspective. They demonstrate the distribution of illness is related to prevalence of risk factors in the whole population, not just the sick. This applies also to mental health: it is distributed normally (not bi-modally) in the population. There is no clear boundary between the general population and people diagnosed with anxiety and depression, in terms of symptomatology or the presence of risk factors. The mean number of mental health symptoms in a population is related to the prevalence of clinical disorder: "this implies that explanations for the differing prevalence rates of psychiatric morbidity must be sought in the characteristics of their parent populations; and control measures are unlikely to succeed if they do not involve population-wide changes" (Huppert, 2005, p. 327).

As a result, targeted intervention for people with a diagnosed condition is not the only effective approach; whole population interventions may shift the distribution of risk factors and symptoms, with disproportionately large benefits to the most vulnerable groups. This underpins many public health interventions, for example a universal requirement to wear seat belts reduces road traffic injury in the sub-set of people involved in accidents. The logic applies to mental as well as physical health. The key point emerging from positive psychology perspectives on public mental health is that there are benefits at a population level from promoting positive well-being, and that whilst targeted interventions for specific groups with a diagnosis may also be necessary, they would not be sufficient to get the desired results.

\section{Social interventions and public mental health}

There is ample evidence for the importance of social causation in psychological distress (Friedli, 2009; Murali \& Oyebode, 2004; Wilkinson \& Pickett, 2010). This raises the question of what can be done: "strategies for preventing distress can be built on a few simple things: education, a fulfilling job, a supportive relationship, and a decent living are to mental health what exercise, diet and not smoking are to physical health" (Mirosky \& Ross, 2003, pp. 273-4). With three out of four 
elements of this prescription relating to careers, it can be justified to explore the relevance of career interventions within a wider context of social interventions to promote mental health.

A weakness of public health policy is that responsibility for it may be restricted to health bodies whose resources are dominated by disease management not prevention, and who lack authority over the areas of life where the root causes of illness can be found (Stoate \& Jones, 2010). The Adelaide Statement on Health in All Policies (WHO/Government of South Australia, 2010) represents an international recognition of the need for 'joined up' government, and that health needs to be addressed in other sectors of social policy. The interdependence of public policy requires a new approach to governance. This view now has a substantial scientific underpinning (e.g. Foresight Mental Capital and Wellbeing Project, 2008). Health prevention requires addressing causal factors and this cannot be done by treatment services: "the drivers of health lie outside the health sector" (Marmot 1999, cited by WHO, 2004c, p. 55). Bambra (2011) takes this argument a stage further by identifying employment as the key factor generating the social inequalities which subsequently lead to health inequalities: "paid work, or the lack of it, is the most important determinant of population health and health inequalities in advanced market democracies" (Bambra, 2011, p. ix).

\section{Career guidance as a public mental health intervention}

The notion that career guidance can contribute to mental health is not new. Herr (1989) and Loughhead (1989) suggest both a preventive and a treatment role for career counselling, and the adoption of behavioural health approaches. Blustein (2008) explicitly suggests there are public policy implications of accepting the centrality of work and career in psychological health. He points to developments in occupational health psychology, vocational rehabilitation and positive psychology as having potential to inform the practice of career advisers and public policy. His contribution is perhaps the most developed in the literature to date. These ideas have not been taken up and developed by others, but there are early signs that this may be beginning to change.

...whilst the funding of careers guidance is commonly justified in terms of its contribution to creating and maintaining an efficiently functioning economy, it could equally be argued that it 
is justifiable in terms of contributing to the health and well-being of the nation. (Bimrose, 2009, p. 1)

Policy goals need not be mutually exclusive. Conceivably if there are health gains from guidance interventions these may result in indirect economic gains, such as reduced demand for health care services, a possibility hinted at by Gillie and Gillie Isenhour (2005) and Mayston (2002). Also guidance has social equity goals, so ameliorating the detrimental health effects of inequality and exclusion may be an aspect of this role

\section{Levels of prevention}

Public health interventions can be classified into three types: primary, secondary, and tertiary prevention. Primary prevention refers to interventions designed to prevent the occurrence of illness in the first place: this is indisputably the most attractive option. Primary prevention could seek to reach the whole population, or target 'at risk' groups. Unemployed people and young people are two key client groups for guidance and also represent obvious targets for primary prevention. There is a vast evidence base demonstrating the detrimental effects of unemployment on mental health (e.g. Paul \& Moser, 2009). Career guidance interventions could benefit unemployed groups in two ways. Firstly, by providing support that accelerated reemployment, such as provision of information on opportunities, and job search coaching. Secondly, by providing support that helps to inoculate against the negative psychological effects of unemployment by reinforcing self-concept, promoting selfefficacy and teaching strategies to stay socially engaged.

Young people (i.e. adolescents and young adults) are not only a key group for guidance services, they are also the age group most likely to experience first onset of mental health conditions. They are exposed to intense social and transition pressures, while biological maturation is not yet complete. Given the evidence that the developmental effects of unemployment on mental health conditions are potentially serious and long lasting, this area must be of particular interest as a target for primary prevention (Allen, Hetrick, Simmons, \& Hickie, 2007; Monroe \& Harkness, 2005). The increase in both the complexity of youth transitions, and the length of time taken to achieve independence, may raise exposure to health risks (Furlong, 2002). 
Career education and guidance interventions could strengthen identity and self-esteem in adolescence, and promote pro-active behaviour. These are valuable outcomes in their own right and associated with positive mental health. The contribution of careers services may also help prevent or reduce the duration of youth unemployment by promoting engagement in education and training, thus limiting exposure to a key risk to health. This is speculative; relatively little is known about the effectiveness of early mental health intervention, and some evidence is inconclusive (Harden, Rees, Shepherd, Ginny, Oliver, \& Oakley, 2001). So this represents a key target for research effort: the potential value of knowledge in this area is great (Allen et al., 2007; Gillham, Shatte \& Freres, 2000). Secondary prevention refers to interventions designed to reduce the duration of a health condition and prevent its re-occurrence. There is an extensive literature suggesting benefits of re-engaging in work, particularly in relation to recovery from mental health conditions (Coutts, 2007; Crowther, Marshall, Bond, \& Huxley, 2001; Seebohm, Grove \& Secker, 2002). Notwithstanding a tendency in the literature to neglect common mental health conditions in favour of severe and enduring conditions (Underwood, Thomas, Williams, \& Thieba, 2007), the evidence for secondary prevention, if not conclusive, is at least promising.

Tertiary prevention refers to measures to limit the detriments associated with chronic and long term conditions. An example might be the use of 'condition management programmes' in the UK, which are health interventions delivered in the context of employment initiatives for long term unemployed adults with health conditions. Cognitive behavioural therapy is the most commonly used psychological treatment in this context (Clayton, Bambra, Gosling, Povall, Misso, \& Whitehead, 2011). Welfare-to-work interventions, even for those with enduring health conditions, tend to focus on rapid placement into employment (Lindsay, McQuaid \& Dutton, 2007).

Career guidance is a not a routine feature of vocational rehabilitation services, but a case could be made that it has a role to play in secondary and tertiary prevention. Its developmental focus on long term life planning may lead to more sustainable outcomes than typical welfare--work services. Alternatively, guidance may provide support to access work, volunteering or learning primarily for therapeutic purposes, so as to gain the health benefits of participating in engaging activities in a social context. This work may benefit from close liaison with mental health services. 
Thus targeted provision for specific groups with a diagnosis should not be ruled out, but primary prevention for the whole population remains the most important arena for the promotion of wellbeing.

\section{Platform for delivery}

It is problematic for social interventions to reach the whole population, in a similar way that fluoridation of water supplies could reduce tooth decay across society. As a result the prime target for public mental health interventions is most often school pupils (Levine, Perkins \& Perkins, 2005; Rothi, 2006) as they represent a large 'captive' target group, with near complete population coverage for an age cohort, and the potential that impacts may have long lasting or multiplying benefits. This is an obvious domain of activity for career guidance services, at least in those nations that have state delivery structures. Indeed some career guidance services may achieve better population coverage than schools, by virtue of contact with disaffected young people and non-attenders, an important atrisk group.

Another clearly defined population for public mental health intervention is employees in the workplace (Barry \& Jenkins, 2007), also a potential domain for the delivery of guidance. Guidance services also reach unemployed adults through specialist agencies, and may be located in public employment services (Sultana \& Watts, 2006), hinting at an answer to this important question:

While there are structures for disseminating interventions for general health, physical health and mental health, there is currently no structure through which we can promote psychological health and well-being. Where do you develop a psychological health delivery system, especially for people who are unemployed? In other words, whose core business is it

to address the psychological effects of unemployment? (Rose \& Harris, 2004, p. 301)

Career guidance services are unusual in that they are likely to have access to several of the key target populations for public mental health interventions. Also, they lack the clinical culture of health services, which may be stigmatising or send an implicit message of incapacity. As a result they represent a viable platform from which to promote positive mental well-being. 


\section{Evidence}

There is a substantial evidence base demonstrating the impact of social and economic factors on mental health, but there is a relative paucity of evidence on the impact of social and economic policy initiatives on mental health, particularly in the field of employment (Candy et al., 2007). Reviews of the literature by Lakey, Mukherjee and White (2001) and Coutts (2010) highlight the 'evidence void' relating to the health impacts of active labour market policies. Jané-Llopis, Barry, Hosman \& Patel (2005) accept there are substantial gaps in the evidence base and some ineffective interventions, but claim that there is a growing theoretical base and body of empirical evidence for the effectiveness of public mental health measures, with the potential for lasting effects on well-being and additional socio-economic benefits. Social interventions are most likely to have indirect effects on health so there is not just a lack of evidence in relation to their effectiveness, and a need to build the evidence base, but also substantial methodological challenges in attempting to do so.

In health related policy making, there are hierarchies of evidence, with greater faith placed in research that is perceived to be more robust. Hughes and Gration (2009) apply this kind of thinking to career guidance interventions and present a five-level evidence hierarchy, locating research designs with strong counterfactuals at the higher levels. Large randomised control trials (RCTs) carry the most weight in these evidence hierarchies. Often described as the 'gold standard' for research, RCTs represent the best design for identifying those effects that can be attributed to an intervention. However the application of methods developed for clinical drug trials to research into social interventions such as counselling remains controversial, and can be criticised for a number of reasons (Timulak, 2008). These include lack of adequate control groups or placebo equivalents, and use of samples that are not typical of those found in practice situations. RCTs may have strong internal validity, but may often have weak ecological validity. Furthermore, RCTs usually require standardisation in 'treatment', which is problematic in guidance interventions. In the terminology of health research, career guidance would be defined as a 'complex intervention' because it typically involves multiple components, combined in ways tailored to the individual (Medical Research Council, 2008). 
Not only do evidence hierarchies privilege RCTs, they also undervalue qualitative research. RCTs may neglect process research illuminating change mechanisms, and build in assumptions in their choice of outcome variables. There is good reason to believe that qualitative evidence has the potential to be highly valuable, particularly when exemplary studies such as Bimrose, Barnes and Hughes (2008) are considered.

Nonetheless when policy makers look for an empirical basis for action, they must turn to concise and authoritative summaries of the evidence. Meta-analyses and systematic reviews of the literature are particularly influential, most notably Cochrane Collaboration reviews (as described by Higgins \& Green, 2008). The inclusion criteria in these reviews are strict, with RCTs given primacy. Such evidence is not currently available in career guidance; most relevant research would not meet the criteria for inclusion, including valuable qualitative research. The narrative approaches preferred by some (e.g. Blustein, Medvide \& Kozan, 2012), irrespective of their merits, do not generate the kind of evidence that influences international public health policy, at least not as isolated studies. Currently national bodies such as the UK's National Institute for Health and Clinical Excellence (NICE) and international bodies such as the WHO or the European Union demonstrate a preference for RCTs in systematic reviews of the scientific literature in guiding public (mental) health policy (e.g. Jané-Llopis et al, 2005; NICE, 2012; WHO, 2004a).

There is hope this may change in future. Some of these sources, whilst privileging RCTs, do acknowledge their limitations and the potential of other kinds of evidence to make a contribution. There are moves towards developing meta-synthesis techniques in the qualitative health research literature, (e.g. Walsh, 2005). Shadish and Myers (2004) discuss the inclusion policy for Campbell Collaboration reviews, a sister organisation to the Cochrane Collaboration, which focuses on social rather than medical interventions. Whilst still giving primacy to randomised trials, they identify a number of reasons to include other research designs in Campbell systematic reviews, to reflect the nature of social science evidence base.

Producing a persuasive evidence base is not inconceivable. Even though there are few systematic reviews addressing social interventions to improve health, some examples are identified by Bambra, Gibson, Sowden, Wright and Petticrew (2010). These include Adams, White, Moffatt, 
Howel and Mackintosh (2006): the effects of welfare benefits advice in healthcare settings; Audhoe, Hoving, Sluiter and Frings-Dresen (2010): the effects of interventions for the unemployed on work participation and mental distress; and Rueda, Chamber, Wilson, Mustard, Rourke and Bayoumi (2012): the effects of return to work on health. Research addressing health outcomes of vocational interventions remains rare; more often employment outcomes are the chosen measure of rehabilitation even in reviews (e.g. Bambra, Whitehead \& Hamilton 2005; Crowther et al., 2001).

There are interesting examples of large RCTs that attempt to manage the challenges to applying this research design to social interventions. Most notable is the work of the Michigan Prevention Research Center (MPRC) who developed a group based job search training intervention for unemployed adults. They produced evidence of positive impacts on mental health variables as well as employment outcomes (Price, Vinokur \& Friedland, 2002); these findings have been replicated internationally, notably in Finland (e.g Vuori, Silvonen, Vinokur \& Price, 2002). This work was developed from the outset with the intention of creating a preventive public mental health intervention (e.g. Price, House \& Gordus, 1985). Their approach represents primary prevention for a mainstream (non-clinical) population of unemployed job seekers including some at risk of developing conditions such as depression. No equivalent research effort exists for career guidance interventions, in spite of claims for their therapeutic value, supported by accounts from counsellors (e.g. Blustein, 1987; Zunker, 2008). Robertson (2013) reviews the available evidence in more detail, and suggests possible causal mechanisms linking career guidance interventions to well-being outcomes.

\section{Conclusion}

Although claims have been made for the therapeutic effects of career counselling, few authors, with the notable exception of Blustein (2008), have sought to extend this logic to the wider sphere of public policy. The potential for career guidance interventions to have a positive effect on mental well-being at a population level has been neglected; it is time to for health to sit alongside economic development, lifelong learning and social equity goals for guidance in international policy discourse. 
There are two significant obstacles to be faced in pursuing a well-being agenda in guidance. Firstly, the governance of career services is usually within education or employment structures: organisations that are not tasked with health objectives and have a limited history of contributing to public health initiatives. Secondly, producing a persuasive evidence base to inform public health policy may require going some way towards adopting the methods used in health research, some of which are problematic to translate to a guidance context.

Nonetheless, a strong rationale can be made that career guidance may impact on well-being. It is clearly important to explore three avenues which can be pursued in parallel: initiating a dialogue with policy makers, developing an empirical evidence base, and considering the implications for service design and delivery. 


\section{References}

Adams, J., White, M., Moffatt, S., Howel, D.M. \& Mackintosh, J. (2006). A systematic review of the health, social and financial impacts of welfare rights advice delivered in healthcare settings. $B M C$ Public Health, 6, 81. doi: 10.1186/1471-2458-6-81.

Allen, N.B., Hetrick, S.E., Simmons, J.G. \& Hickie, I.B. (2007). Early intervention for depressive disorders in young people: the opportunity and the (lack of) evidence. Medical Journal of Australia, 187 (7), S15-S17.

Audhoe, S.S., Hoving, J.L., Sluiter, J.K. \& Frings-Dresen, M.H.W. (2010). Vocational interventions for unemployed: effects on work participation and mental distress: a systematic review. Journal of Occupational Rehabilitation, 20, 1-13. doi: 10.1007/s10926-009-9223-y.

Bambra, C. (2011). Work, worklessness and the political economy of health. Oxford: Oxford University Press.

Bambra, C., Gibson, M., Sowden, A., Wright, K. \& Petticrew, M. (2010). Tackling the wider social determinants of health and health inequalities: evidence from systematic reviews. Journal of Epidemiology and Community Health, 64, 284-291. doi:10.1136/jech.2008.082743.

Bambra, C., Whitehead, M. \& Hamilton, V. (2005). Does 'welfare to work' work? A systematic review of the effectiveness of the UK's welfare-to-work programmes for people with a disability or chronic illness. Social Science and Medicine, 60, 1905-1918. doi: 10.1016/j.socscimed.2004.09.002

Barry. M.M. \& Jenkins, R. (2007). Implementing mental health promotion. Philadelphia: Churchill Livingstone/Elsevier.

Bimrose, J. (2009). Careers guidance, identity and development. Warwick: University of Warwick, Institute for Employment Research.

Bimrose, J., Barnes, S.A. \& Hughes, D. (2008). Adult career progression and advancement: a five year study of the effectiveness of guidance. Coventry: Warwick Institute for Employment Research/ Department for Innovation, Universities and Skills

Blustein, D.L. (1987). Integrating career counselling and psychotherapy: a comprehensive treatment strategy. Psychotherapy, Research, Practice, Training, 24, 794-799. doi: 10.1037/h0085781.

Blustein, D.L. (2008). The role of work in psychological health and well-being: a conceptual, historical and public policy perspective. American Psychologist, 63, 228-240. doi: 10.1037/0003066X.63.4.228

Blustein, D.L., Medvide, M.B. \& Kozan, S. (2012). A tour of a new paradigm: relationships and work. The Counselling Psychologist, 40, 243-254. doi: 10.1177/0011000011429032.

Bok, D. (2010) The politics of happiness: what governments can learn from the new research on well-being. Princetown: Princetown University Press.

Booth, P. (Ed) (2012). ...And the pursuit of happiness: wellbeing and the role of Government. London: the Institute of Economic Affairs.

Candy, B., Cattell, V., Clark, C. \& Stansfeld, S.A. (2007). The health impact of policy interventions tackling the social determinants of common mental disorder. Journal of Public Mental Health, 6, 28-39. doi: 10.1108/17465729200700012.

CEDEFOP (2011). Lifelong guidance across Europe: reviewing policy progress and future prospects

Working paper 11. European Centre for the Development of Vocational Training. Luxembourg: Publications Office of the European Union. doi: 10.2801/92019.

Clayton, S., Bambra, C., Gosling, R., Povall, S., Misso, K. \& Whitehead, M. (2011). Assembling the evidence jigsaw: insights from a systematic review of UK studies of individual-focused return to work initiatives for disabled and long-term ill people. BMC Public Health, 11, 170. doi: 10.1186/1471-2458-11170.

Coutts, A.P. (2010). Active labour market programmes (ALMPs) and health: an evidence base. 
Review prepared for the strategic review of health inequalities in England post 2010 (Marmot review). London: University College London Institute of Health Equity.

Coutts, P. (2007). Mental health, recovery and employment. In S. Bradstreet \& W. Brown (Eds) SRN discussion paper series. Report no. 5. Glasgow: Scottish Recovery Network.

Crowther, R.E., Marshall, M., Bond, G.R. \& Huxley, P. (2001). Helping people with severe mental illness to obtain work: a systematic review. British Medical Journal, 322, 204-208. doi: 10.1136/bmj.322.7280.204.

Delle Fave, A.D. \& Massimini, F. (2005). The relevance of subjective well-being to social policies: optimal experience and tailored intervention. In F.A. Huppert, N. Baylis \& B. Keverne (Eds.) The science of well being (pp. 379-404). Oxford: Oxford University Press.

Diener, E. \& Seligman, M.E.P. (2004). Beyond money: Toward an economy of well-being. Psychological Science in the Public Interest, 5, 1-31. doi: 10.1111/j.0963-7214.2004.00501001.x.

Donovan, N. \& Halpern, D. (2002). Life satisfaction: the state of knowledge and implications for government. London: Prime Minster's Office Strategy Unit.

Easterlin, Richard A. (1974). Does economic growth improve the human lot? Some empirical evidence. In: P.A. David and M.W. Reder (Eds), Nations and households in economic growth: essays in honor of Moses Abramovitz (pp. 89-125) New York: Academic Press.

Ecclestone, K. \& Hayes, D. (2008). The dangerous rise of therapeutic education. London: Routledge.

European Lifelong Guidance Policy Network (2010). Lifelong guidance policies: work in progress. Jyväskylä, Finland: ELPN.

Field, J. (2009). Well-being and happiness: inquiry into the future of lifelong learning. ILF Thematic paper no.4. Leicester: National Institute of Adult and Continuing Education.

Foresight Mental Capital and Wellbeing Project (2008) Final Report. London: The Government Office for Science.

Friedli, L. (2009). Mental health, resilience and inequalities. Copenhagen: World Health Organisation.

Furlong, A. (2002). Youth transitions and health: a literature review. Edinburgh: Health Education Board for Scotland.

Gillham, J.E., Shatte, A.J. \& Freres, D.R. (2000). Preventing depression: a review of cognitive behavioural and family interventions. Applied \& Preventive Psychology, 9, 63-88. doi: 10.1016/509621849(00)80007-4.

Gillie, S. \& Gillie Isenhour, M. (2005). The educational, social and economic value of informed and considered career decisions. Alexandria, VA: America's Career Resource Network Association. Retrieved 10 February 2013 from: http://www.californiacareers.info/downloads/handouts/iccd update 2005.pdf

Halpern, D. (2010). The hidden wealth of nations. Cambridge: Polity Press.

Hanson, E. (2006). Career guidance: a resource handbook for low and middle income countries. Geneva: International Labour Organisation.

Harden, A., Rees, R. , Shepherd, J. Ginny, B. , Oliver, S. \& Oakley, A. (2001). Young people and mental health: systematic review of research on barriers and facilitators. London: EPPI-Centre.

Herr, E.L. (1989). Career development and mental health. Journal of Career Development, 16, 5-18. doi: 10.1007/BF01354263

Higgins, J.P.T \& Green, S. (Eds.) (2008) Cochrane handbook for systematic reviews of interventions (Cochrane Book Series). Chichester: The Cochrane Collaboration/Wiley-Blackwell.

Hughes, D.M. \& Gration, G. (2009). Evidence and impact: careers and guidance-related interventions. CfBT Education Trust/DMH Associates Accessed online from: http://www.eep.ac.uk/DNN2/Portals/O/IAG/E\&I(Synthesis)_FINAL(W).pdf on 8/4/2013.

Huppert, F.A. (2004). A population approach to positive psychology: the potential for population 
interventions to promote well-being and prevent disease. In: P.A. Linley \& S. Joseph (Eds), Positive psychology in practice (pp. 693-709) Hoboken, NJ: John Wiley.

Huppert, F.A. (2005). Positive mental health in individuals and populations. In F.A. Huppert, N. Baylis \& B. Keverne (Eds.) The science of well being (pp. 307-342). Oxford: Oxford University Press.

International Labour Organisation (2012). Global trends 2012: preventing a deeper jobs crisis. Geneva: ILO.

Jané-Llopis, E. \& Anderson, P. (2005). Mental health promotion and mental disorder prevention: a policy for Europe. Nijmegen: Radboud University Nijmegen.

Jané-Llopis, E., Barry, M., Hosman, C. \& Patel, V. (2005). Mental health promotion works: a review. IUHPE Promotion and Education Supplement, 2, 9-25. doi: 10.1177/10253823050120020103x.

Keyes, C.L.M. (2002). The mental health continuum: from languishing to flourishing in life. Journal of Health and Social Behavior, 43, 207-222

Lakey, J., Mukherjee, A. \& White, M. (2001). Youth unemployment, labour market programmes and health: a review of the literature. London: Policy Studies Institute.

Layard, R. (2005). Happiness: lessons from a new science. London: Penguin.

Lazarus, R.S. (2003). Does the positive psychology movement have legs? Psychological Enquiry, 14, 93-109. doi: 10.1207/S15327965PLI1402_02.

Levine, M., Perkins, D.D. \& Perkins, D.V. (2005). Principles of community psychology: perspectives and applications. (3rd edition). New York: Oxford University Press.

Lindsay, C., Mcquaid, R.W. \& Dutton, M. (2007). New approaches to employability in the UK: combining "human capital development" and "work first" strategies. Journal of social policy, 36, 4: 539560.

Loughead, T.A. (1989). Career development curriculum (CDC) for the mentally ill. Journal of Career Development, 16, 53-62. doi: 10. 1007/BF01354267

Mayston, D. (2002). Assessing the benefits of career guidance. Occasional Paper. Derby: Centre for Guidance Studies, University of Derby.

McKee-Ryan, F.M. \& Song, Z., Wanbeg, C.R. \& Kinicki, A.J. (2005). Psychological and physical well being during unemployment: A meta-analytic study. Journal of Applied Psychology, 90, 53-76. doi: 10.1037/0021-9010.90.1.53.

Medical Research Council (2008). Developing and evaluating complex interventions: new guidance. MRC. Retreived 19 June 2012 from: http://www.mrc.ac.uk/Utilities/Documentrecord/index.htm?d=MRC004871

Mirowsky, J. \& Ross, C.E. (2003). The social causes of psychological distress. New York: Walter de Gruyter.

Monroe, S.M. \& Harkness, K.L. (2005). Life stress, the "kindling" hypothesis, and the recurrence of depression: considerations from a life stress perspective. Psychological Review, 112, 417-445. doi: 10.1037/0033-295X.112.2.417.

Murali, V. \& Oyebode, F. (2004). Poverty, social inequality and mental health. Advances in psychiatric treatment, 10, 216-224. doi: 10.1192/apt.10.3.216

National Institute for Health and Clinical Excellence (2012). Methods for development of NICE public health guidance ( $3^{\text {rd }}$ edition) London: NICE. Retrieved 30/5/13 from: http://publications.nice.org.uk/methods-for-the-development-of-nice-public-health-guidance-thirdedition-pmg4

Office for National Statistics (2011). Measuring subjective wellbeing in the UK. Newport: ONS.

Organisation for Economic Co-operation and Development (2010). Career guidance: a handbook for policy makers. Paris: OECD/European Commission.

Paul, K.I. \& Moser, K. (2009). Unemployment impairs mental health: Meta-analyses. Journal of Vocational Behaviour, 74, 264-282. doi: 10.1016/j.jvb.2009.01.001 
Pavot, W. \& Diener, E. (2004). Findings on subjective well-being: applications to public policy, clinical interventions and education. In: P.A. Linley \& S. Joseph (Eds) Positive psychology in practice (pp. 679-692). Hoboken, NJ: John Wiley.

Price, R.H., House, J., \& Gordus, J.P. (1985). Exploring work as an arena for prevention research: The Michigan Prevention Research Center. Journal of Prevention in Human Services, 3, 101-116. doi: 10.1300/J293v03n04_10.

Price, R. H., Vinokur, A.D., \& Friedland, D.S. (2002). The job seeker role as resource in achieving reemployment and enhancing mental health new directions. In: A. Maney \& J. Ramos (Ed.) Socioeconomic conditions, stress and mental health disorders: Toward a new synthesis of research and public policy. Washington, D.C: NIMH.

Robertson, P.J. (2013). The well-being outcomes of guidance. British journal of guidance and counselling, doi: 10.1080/03069885.2013.773959

Rose, V. \& Harris, E. (2004). From efficacy to effectiveness: case studies in unemployment research. Journal of Public Health, 26, 297-302. doi: 10.1093/pubmed/fdh146.

Rothi, D.M. (2006). Mental health help-seeking and young people: a review. Pastoral Care, September: 4-13. doi: 10.1111/j.1468-0122.2006.00373.x.

Rueda, S., Chamber, L., Wilson, M., Mustard, C., Rourke, S.B., Bayoumi, A. (2012). Association of returning to work with better health in working-aged adults: a systematic review. American journal of public health, 102, 541-556. doi: 10.2105/AJPH.2011.300401

Seebohm, P., Grove, B. \& Secker, J. (2002). Working towards recovery: putting employment at the heart of refocused mental health services. London: Kings College.

Shadish, W. \& Myers, D. (2004). Research design policy brief. Oslo: The Campbell Collaboration. Retrieved 9/4/13 from: http://www.campbellcollaboration.org/artman2/uploads/1/C2_Research_Design_Policy_Brief-2.pdf

Stiglitz, J.E., Sen, A. \& Fitoussi, J-P. (2009). Report of the commission on the measurement of economic performance and social progress. Paris: Commission on the Measurement of Economic Performance and Social Progress. Retrieved 11 July 2012 from: http://www.stiglitz-sen-fitoussi.fr

Stoate, H. \& Jones, B. (2010). Work, the grand cure: how changing the way Britain works will be good for our health. London: The Fabian Society.

Stuckler, D., Basu, S., Suhrcke, M., Coutts, A. \& Mckee, M. (2009). The public health effect of economic crises and alternative policy responses in Europe: an empirical analysis. The Lancet, 374, 31523. doi:10.1016/S0140-6736(09)61124-7.

Sultana, R.G. \& Watts, A.G. (2006). Career guidance in Europe's public employment services: trends and challenges. International Journal for Educational and Vocational Guidance, 6, 29-46. doi: 10. 1007/s10775-006-0001-5

The Economist (2006). Economics discovers its feelings. The Economist. December 23 $3^{\text {rd }}: 35-37$.

Timulak, L. (2008). Research in psychotherapy and counselling. London: Sage

Underwood, L., Thomas, J., Williams, T., Thieba, A. (2007). The effectiveness of interventions for people with common mental health problems on employment outcomes: a systematic rapid evidence assessment. London: EPPI-Centre, Social Science Research Unit, Institute of Education, University of London.

van Deurzen, E. (2009). Psychotherapy and the quest for happiness. London: Sage.

Veenhoven, R. (2004). Happiness as a public policy aim: the greatest happiness principle. In: P.A. Linley \& S. Joseph (Eds) Positive psychology in practice (pp. 658-678). Hoboken, NJ: John Wiley.

Vuori, J., Silvonen, J., Vinokur, A.D., \& Price, R.H. (2002). The Työhön job search program in Finland: benefits for the unemployed with risk of depression or discouragement. Journal of Occupational Health Psychology, 7, 5-19. doi: 10.1037/1076-8998.7.1.5.

Waddell, G. \& Burton, A.K. (2006). Is work good for your health and well-being? London: Department for Work and Pensions. 
Walsh, D. (2005). Meta-synthesis method for qualitative research: a literature review, Journal of Advanced Nursing, 50, 204-211. doi: 10.1111/j.1365-2648.2005.03380.x

Warr, P. (2007). Work, happiness and unhappiness. Mahwah, NJ: Lawrence Erlbaum.

Watts, A.G. \& Sultana, R. (2004). Career guidance policies in 37 countries: contrasts and common themes. International Journal for Vocational and Educational Guidance, 4, 105-122. doi: 10.1007/s10775005-1025-y.

Wilkinson, R. \& Pickett, K. (2010). The spirit level: why equality is better for everyone. ( $2^{\text {nd }}$ edition). London: Penguin.

World Health Organisation (2002). Prevention and promotion in mental health. Geneva: WHO.

World Health Organisation (2004a). Prevention of mental disorders: effective interventions and policy options. Summary report. Geneva: WHO

World Health Organisation/World Mental Health Consortium (2004b). Prevalence, severity and unmet need for treatment of mental disorder. Journal of American Medical Association, 291, 2581-89.

World Health Organisation (2004c). Promoting mental health: concepts, emerging evidence, practice. Summary report. Geneva: WHO.

World Health Organisation (2005). Mental health: strengthening mental health promotion. Fact sheet no. 220. Geneva: WHO

World Health Organisation (2011). Global burden of mental disorders and the need for a comprehensive, coordinated response from health and social sectors at the country level: Report by the Secretariat.

World Health Organisation/Government of South Australia (2010). Adelaide statement on health in all policies. Adelaide: WHO.

Zunker, V. (2008). Career, work and mental health: integrating career and personal counseling. London: Sage. 